\title{
Tsafon
}

Revue d'études juives du Nord

$72 \mid 2016$

Juifs, Israéliens, dans la littérature française et israélienne

\section{Nurit Levy, L'Intellectuel juif entre histoire et fiction}

\section{Michèle Tauber}

\section{(2) OpenEdition \\ Journals}

Édition électronique

URL : https://journals.openedition.org/tsafon/499

DOI : $10.4000 /$ tsafon.499

ISSN : 2609-6420

Éditeur

Association Jean-Marie Delmaire

\section{Édition imprimée}

Date de publication : 1 décembre 2016

Pagination : 186-188

ISSN : 1149-6630

\section{Référence électronique}

Michèle Tauber, « Nurit Levy, L'Intellectuel juif entre histoire et fiction », Tsafon [En ligne], 72 | 2016, mis en ligne le 31 mai 2018, consulté le 24 juin 2021. URL : http://journals.openedition.org/tsafon/499 ; DOI : https://doi.org/10.4000/tsafon.499

Ce document a été généré automatiquement le 24 juin 2021.

Tsafon. Revues d'études juives du Nord 


\title{
Nurit Levy, L'Intellectuel juif entre histoire et fiction
}

\author{
Michèle Tauber
}

\section{RÉFÉRENCE}

Nurit Levy, L'Intellectuel juif entre histoire et fiction. S. Doubrovsky, Ph. Roth, A.B.

Yeoshua, Paris, Classiques Garnier, 2015, 495 p., $49 €$.

1 L'Intellectuel juif entre histoire et fiction n'est pas un simple essai littéraire : il s'agit d'une étude particulièrement fouillée à la fois sur les plans littéraire, historique, sociologique et anthropologique de ces deux personnages que sont le «juif» et «l'intellectuel». L'auteure ouvre son propos avec l'apparition de l'intellectuel juif en France à la fin du $\mathrm{XIX}^{\mathrm{e}}$ siècle, et poursuit avec ses épigones aux États-Unis et en Israël. La seconde partie est consacrée à l'université et l'intertextualité dans les romans étudiés pour aboutir à une réflexion sur la transgression et l'identité.

\section{L'intellectuel juif : une figure née de l'histoire}

2 Nurit Levy présente ce personnage comme une réponse à un modèle socioculturel né en Europe à la charnière $\mathrm{du} \mathrm{xx}^{\mathrm{e}}$ siècle en réponse à deux phénomènes sociaux: l'antisémitisme et le sionisme. En France, c'est l'Affaire Dreyfus qui déclenche l'engagement des hommes de lettres dans la Cité, et parmi eux les premiers intellectuels juifs. En 1925 est fondée la Revue Juive, dans laquelle est mise en avant l'importance de l'identité juive à travers le langage. C'est dans ce contexte que grandit Serge Doubrovsky (né en 1928) dont l'existence et l'identité seront à jamais marquées par la persécution nazie. Mais Doubrovsky se réfère aussi constamment aux « écrivains mythiques de l'histoire littéraire française » (p.72). L'un de ses romans s'intitule Un amour de soi en hommage à Proust mais c'est surtout à partir de l'autobiographie 
sartrienne que Doubrovsky va construire une œuvre tout entière empreinte du doute existentiel. Son écriture éclatée reflète la cassure opérée d'avec le monde extérieur.

\section{L'intellectuel juif au pays de la liberté}

3 Aux États-Unis, le terme « intellectuel » a été introduit dès la fin du XIX siècle dans son acception française. Nurit Levy analyse avec précision la mutation vécue par l'intellectuel américain dans la période de l'entre-deux-guerres, lorsqu'apparaît «l'intellectuel public » qui va à la rencontre de son public dans les coffee houses de Greenwich Village. Après la Seconde Guerre mondiale, nombreux sont les écrivains, journalistes et éditeurs qui vont intégrer l'université pour mener à bien leur carrière. L'auteure explique comment s'opère la transformation progressive de l'intellectuel américain qui bascule de l'espace public à l'espace universitaire. L'écrivain Philip Roth en est le représentant le plus célèbre : son roman, La Tache, est une saga romanesque de la political correctness, phénomène social qui apparaît en Amérique avec les théories postmodernes de Jacques Derrida et autres philosophes français. Philip Roth démonte cette théorie visant à l'origine à la libération de la pensée et du langage et qui, à la suite d'enjeux politiques, est employée par le pouvoir à des fins répressives (pp. 132-150).

\section{Israël, le « lieu » et l'intellectuel juif}

Israël est le troisième lieu où Nurit Levy explore la figure de l'intellectuel juif. A.B. Yehoshua fait partie des écrivains de la "génération de l'État ». Ses œuvres décrivent les nombreux problèmes sociaux du jeune État. Dans le même temps l'intervention de l'écrivain dans les débats publics israéliens et son engagement intellectuel pour certaines causes politiques renvoient à une tradition juive bien établie en Europe centrale et orientale au XIX siècle. Dans La mariée libérée, Yohanan Rivline, comme Yehoshua, se préoccupe de questions concernant Israël. Le choix de son métier d'orientaliste annonce d'emblée au lecteur le sujet principal de l'intrigue, à savoir mieux connaître la communauté arabe vivant en Israël ou dans les territoires occupés. Les interrogations de Riveline à travers tout le roman témoignent de la nécessité pour l'écrivain de se rapprocher des voisins arabes car, à ses yeux, ils font partie de l'identité israélienne. La recherche universitaire de Rivline qui a souvent recours à des idées reçues semble parfois conventionnelle. Miller, un collègue chercheur, représentant de l'approche postmoderne, préfigure le déclin des théories orientalistes à la fin du $\mathrm{xx}^{\mathrm{e}}$ siècle qui n'offrent pas de réponse aux problèmes actuels du monde arabe (p. 180).

\section{L'identité et la transgression dans les romans}

5 Cette partie analyse l'attitude adoptée par l'intellectuel juif dans la sphère intime, et tout particulièrement leur rapport à l'identité juive qui laisse plus d'une fois apparaître la tentation de la transgression à travers l'écriture.

6 Nurit Levy définit cet élan vers la transgression comme une caractéristique du judaïsme depuis l'Antiquité. En effet, explique-t-elle, « depuis le commencement du judaïsme, la révolte contre Dieu s'inscrit dans la tradition et constitue un mode d'expression, notamment chez les prophètes" (p. 348). Ce modèle de comportement se trouve 
enraciné dans la culture et la conscience juives. Ainsi Doubrovsky et Roth se rejoignent dans l'expression d'une sexualité débordante. Dans La Mariée libérée, tous les personnages sont attirés par l'univers de l'Autre qu'ils aspirent à atteindre en pénétrant son territoire.

7 L'écriture elle-même devient transgression, surtout chez Doubrovsky qui imite l'oralité et qui, tout en se réclamant du style de Céline, procède par inversion macabre : «il s'agit de subvertir une écriture passionnément antisémite, afin de produire une écriture profondément juive qui s'ancre dans le destin de son peuple » (p. 389).

Dans La mariée libérée, l'histoire de la violation d'un tabou est au cœur même de l'intrigue. Nurit Levy analyse subtilement les trois sortes de tabous reliés à la transgression dans le roman de Yehoshua : l'anthropophagie, l'inceste et l'écrit.

\section{Identité et dédoublement : les figures du clivage}

9 Depuis les origines bibliques, l'identité juive dans toute sa complexité a souvent suscité chez les non-juifs des réactions allant de la fascination à la haine. Mais de la même façon, au cours de l'histoire, les Juifs ont été attirés par l'Autre, représenté par l'univers non-juif. Pour A.B. Yehoshua, même après la création de l'État d'Israël, ce désir de s'approprier l'identité de l'Autre subsiste et régit les rapports entre Juifs et Arabes en Israël. Semblablement, selon Nurit Levy, Roth et Doubrovsky exposent une identité juive à la fois double et clivée qu'ils dépeignent à travers leurs personnages et qui traduit bien cette division interne du personnage juif.

\section{Conclusion}

Dans sa conclusion, Nurit Levy insiste sur le fait que, dès sa " naissance », l'intellectuel est marqué par une dimension de libération et d'opposition. La question de la dualité est également centrale dans les trois œuvres et l'intellectuel juif semble à jamais marqué par la scission de son identité. À l'ère du postmodernisme, la figure de l'intellectuel juif est remise en question dans son rapport à la société, à l'Autre, et à sa propre identité à travers le microcosme universitaire où le savoir est désormais dominé par les rapports de force et non plus par la connaissance de soi et du monde. 